\title{
Assessment of ultrafine particles in Portuguese preschools: levels and exposure doses
}

\author{
J.Fonseca, K. Slezakova, \\ S. Morais, M. C. Pereira
}

\begin{abstract}
The aim of this work was to assess ultrafine particles (UFP) number concentrations in different microenvironments of Portuguese preschools and to estimate the respective exposure doses of UFP for 3-5-year-old children (in comparison with adults). UFP were sampled both indoors and outdoors in two urban (US1, US2) and one rural (RS1) preschool located in north of Portugalfor 31 days. Total levels of indoor UFP were significantly higher at the urban preschools (mean of $1.82910^{4}$ and $1.32910^{4}$ particles $/ \mathrm{cm}^{3}$ at US1 an US2, respectively) than at the rural one $\left(1.15910^{4}\right.$ particles $\left./ \mathrm{cm}^{3}\right)$. Canteens were the indoor microenvironment with the highest UFP (mean of $5.17910^{4}$, $3.28910^{4}$, and $4.09910^{4}$ particles/ $\mathrm{cm}^{3}$ at US1, US2, and RS1), whereas the lowest concentrations were observed in classrooms $\left(9.31910^{3}, 11.3910^{3}\right.$, and

$7.14910^{3}$ particles/ $\mathrm{cm}^{3}$ at US1, US2, and RS1). Mean indoor/outdoor ratios (I/O) of UFP at three preschools were lower than 1 (0.54-0.93), indicating that outdoor emissions significantly contributed to UFP indoors. Significant correlations were obtained between temperature, wind speed, relative humidity, solar radiation, and ambient UFP number concentrations. The estimated exposure doses were higher in children attending urban preschools; 3-5-yearold children were exposed to 4-6 times higher UFP doses than adults with similar daily schedules.
\end{abstract}

Key words: ultrafine particles; preschools; indoor/out- door air; children; exposure dose.

\section{Practical Implications}

This study reports information on ultrafine particles (UFPs) in various indoor and outdoor microenvironments (canteens, classrooms, gymnasiums, and outdoor) of urban and rural preschools. It identifies the potential sources and origins, characterizes the influence of meteorological parameters on UFP levels, and performs a comparison with other existing international studies. To this date, relatively few studies have investigated UFP in preschools (none in Portugal) and none assessed exposure dose for different age-groups. The obtained findings showed that levels of UFP in various microenvironments of schools differed significantly. Therefore, to obtain an accurate representation of child's overall preschool exposure profiles, the exposures occurring in these different microenvironments should be always accounted for.

\section{Introduction}

Up to this date, various studies have reported the health risks caused by exposure to particulate matter (Brunekreef et al., 2009; Cassee et al., 2013). In the last years, the scientific attention focused on ultrafine parti- cles (UFP), that is, particles with aerodynamic diame-

ter smaller than $0.1 \mathbf{1 m}$, because evidence indicates that UFP may have a greater potency to cause adverse health effects than large particles (Diapouli et al., 2007; Kumar et al., 2013, 2014). UFP contribute very little to overall particle mass, but they dominate the number concentrations (Morawska et al., 2008). When compared with larger particles, UFP have higher parti- cle number concentration, surface area, and larger concentrations of adsorbed (or condensed) toxic pollutants per unit mass (Sioutas et al., 2005). Due to their smaller sizes, UFP can penetrate cell membranes and deposit in the brain tissues and secondary organs (Donaldson et al., 2001; Semmler et al., 2004; Unfried et al., 2007). Combined effects of UFP high surface area and potentially toxic composition may promote physical and chemical reactions inside the organisms that can further result in adverse health outcomes (Kumar et al., 2011; Stone et al., 2007). Studies have shown that exposures to UFP are associated with 
impaired lung function and pulmonary defense mechanisms, inflammatory responses, asthma, worsening of respiratory diseases and allergic conditions, cardiovascular problems, and even with carcinogenic and genotoxic consequences (Ferreira et al., 2013; Stanek et al., 2011; Terzano et al., 2010).

Ultrafine particles are emitted to atmosphere by combustion processes (associated mostly with emission from traffic or industrial sources; Kumar et al., 2010), formed by nucleation and condensation of hot supersaturated vapors while being cooled to ambient temperatures (Sioutas et al., 2005), and by chemical reactions in the atmosphere (Morawska et al., 2008). In addition, indoor UFP may be emitted from indoor combustions (cooking, smoking, and candle use) and result from occupant-related activities (consumer prod- ucts, paining, and cleaning) (Bhangar et al., 2011; Long et al., 2000; Morawska et al., 2003; Wallace, 2006).

The complexity of UFP exposure (spatial variability, indoor sources, infiltration of UPF from various outdoor emission sources, seasonal variability in concentrations and composition; Sioutas et al., 2005) indicates the need to further study this pollutant to fully comprehend its impacts on human health. This is especially relevant for sensitive groups. Young children in particular are very susceptible to air pollution (Schwartz, 2004) because they receive a higher dose of airborne particles relative to lung size compared with adults, while at the same time, their physiological and immunological systems are still developing (Burtscher and Schfepp, 2012; Morawska et al., 2013). In Portugal, young children spend approximately $30 \%$ of their time (7-8 h/day) at preschools, which raises interest in understanding of air pollution in these environments. Nevertheless, as the importance of UFP has been recognized recently, there have been only few studies on UFP levels in schools (Buonanno et al., 2012, 2013a; Clausen et al., 2012; Diapouli et al., 2008; Fromme et al., 2007; Guo et al., 2010; Kim et al., 2011; Morawska et al., 2009; Mullen et al., 2011; Norbáck et al., 2011; Rumchev et al., 2007; Weichenthal et al., 2008; Zhang and Zhu, 2012) and only some of these studies investigated the correlation with outdoor traffic or indoor processes; as far it is known no study was pub- lished on UFP levels in Portuguese schools. In addi- tion, during the school time, children move between different microenvironments (classroom, gyms, outdoor playgrounds, etc.) where levels of UFP may vary greatly (Zhang and Zhu, 2012). Therefore, quanti- fication of UFP in these specific microenvironments is essential to correctly assess child's overall school expo- sure to UFP.

The aim of this work was to study UFP levels in urban and rural preschools in the north of Portugal. The specific objectives of this work were: (i) to quantify UFP number concentrations in different microenviron- ments of urban and rural preschools and to compare the attained results with other international studies; (ii) to assess the impacts of outdoor UFP to indoor air quality in preschools; and (iii) to estimate exposure doses of UFP for 3-5-year-old children (in comparison with adults).

Materials andmethods

Characterization of sampling sites

Ultrafine particle were consecutively measured at three preschools in Portugal for 31 days (May-June) of 2013. Preschools are educational establishments that provide education for 3-5-year-old children, prior to the beginning of compulsory attendance at primary schools. Specifically in Portugal, 'preschools' referred to institutions that are directly operated by primary schools. In this work, the preschools were selected to represent different environments. Two preschools (US1 and US2) were situated in Oporto Metropolitan Area in Paranhos district (north of Portugal); previously, it was demonstrated that vehicular traffic emissions are the main pollution source in this area (Slezakova et al., 2011, 2013). The third preschool RU1 was located in Xisto also in the north of Portugal but in a rural zone. The detailed characteristic of all three preschools are presented in Table 1.

In all three preschools, UFP were simultaneously measured at different microenvironments, namely in classrooms (2-3) situated on ground and first floor, and in canteen (1). UFP were also measured in gymna- sium or playroom, if existent (Table 1). The character- istics of each studied microenvironment (volume, area, occupancy patterns, number of individuals) as well as construction properties (construction materials, venti- lation mechanisms, and temperature and relative humidity) are summarized in Tables S1-S3.

To better understand the impacts of outdoor UFP emissions to indoor preschool environments, the levels of UFP were concurrently measured in ambient air (i.e., outdoor).

The traffic densities were estimated for each preschool (Table 1). During two consecutive days (avoiding Mondays and Fridays), the number of road vehicles was manually counted between 5 a.m. to 12 p.m. during $10 \mathrm{~min}$ of each hour. These data were used to better describe the surroundings of selected preschools.

\section{Sample collection}

Ultrafine particle number concentrations in size range $0.02-1 \mathrm{Im}$ were measured by condensation particle counters - TSI P-Trak ${ }^{\mathrm{TM}}$ (UPC 8525; TSI Inc., Shoreview, MN, USA). The instrument operates on the principle of condensing $100 \%$ grade isopropyl alcohol 
Table 1 Characterization of the studied pre-schools and meteorological conditions during the sampling campaigns

\begin{tabular}{|c|c|c|c|c|c|}
\hline School & Description & Location & Traffic density data & $\begin{array}{l}\text { Studied } \\
\text { microenvironments }\end{array}$ & $\begin{array}{l}\text { Outdoor meteorological } \\
\text { parameters: mean } \pm \text { s.d. }\end{array}$ \\
\hline US1 & $\begin{array}{l}\text { Private school } \\
\text { Built in } \\
1940 \\
\text { Two-floors } \\
\text { building Enrolled }\end{array}$ & $\begin{array}{l}\text { Urban -traffic } \\
\text { Situated on moderately } \\
\text { trafficked street }\end{array}$ & $\begin{array}{l}\text { Mean: } 16 \text { cars/min } \\
\text { peak hours: } \\
8: 30 \text { h }(27 \text { cars/min }) \\
18: 30 \mathrm{~h}(25 \text { cars } / \mathrm{min})\end{array}$ & $\begin{array}{l}\text { Indoors: } \\
\text { classrooms (3) } \\
\text { canteen (1) } \\
\text { playroom (1) } \\
\text { Outdoors: school yard }\end{array}$ & $\begin{array}{l}\mathrm{T}: 17.5 \pm 2.5^{\circ} \mathrm{C} \\
\text { RH: } 56.3 \pm 8.0 \% \\
\text { WS: } 16.0 \pm 5.5 \mathrm{~km} / \mathrm{h} \\
\text { Precipitation: } 0.3 \pm 0.0 \mathrm{~mm}\end{array}$ \\
\hline US2 & $\begin{array}{l}\text { Private school } \\
\text { Built in } \\
1905 \\
\text { Three-floors } \\
\text { building Enrolled } \\
\text { (30: 3-5 years) }\end{array}$ & $\begin{array}{l}\text { Urban - traffic } \\
\text { Intersection of moderate } \\
\text { and low trafficked street }\end{array}$ & $\begin{array}{l}\text { Mean: } 13 \text { cars/min } \\
\text { peak hours: } \\
\text { 8:30 h }(21 \text { cars/min }) \\
\text { 14:30 h }(18 \text { cars/min }) \\
\text { 18:30 h }(18 \text { cars/min })\end{array}$ & $\begin{array}{l}\text { Indoors: } \\
\text { classrooms (3) } \\
\text { canteen (1) } \\
\text { gymnasium (1) } \\
\text { Outdoors: school yard }\end{array}$ & $\begin{array}{l}\mathrm{T}: 15.3 \pm 1.9^{\circ} \mathrm{C} \\
\text { RH: } 67.0 \pm 8.0 \% \\
\text { WS: } 19.0 \pm 6.7 \mathrm{~km} / \mathrm{h} \\
\text { Precipitation: } 3.5 \pm 0.1 \mathrm{~mm}\end{array}$ \\
\hline RS1 & $\begin{array}{l}\text { Public school } \\
\text { Built in } \\
1981 \\
\text { Two-floors } \\
\text { building Enrolled } \\
\text { (20: } 3-5 \text { years) } \\
\text { School constructed for children } \\
\text { with special needs; 3-5 } \\
\text { years old kept in separately } \\
\text { from olderones }\end{array}$ & Rural & $\begin{array}{l}\text { Mean: < } 1 \text { car/min } \\
\text { peak hours: } \\
8: 30 \mathrm{~h}(1 \mathrm{car} / \mathrm{min}) \\
12: 00 \mathrm{~h}(1 \mathrm{car} / \mathrm{min}) \\
17: 30 \mathrm{~h}(2 \text { cars/min })\end{array}$ & $\begin{array}{l}\text { Indoors: } \\
\text { classrooms (2) } \\
\text { canteen (1) } \\
\text { Outdoors: school yard }\end{array}$ & $\begin{array}{l}\mathrm{T}: 16.7 \pm 1.1^{\circ} \mathrm{C} \\
\text { RH: } 82.0 \pm 5.5 \% \\
\text { WS: } 15.4 \pm 5.3 \mathrm{~km} / \mathrm{h} \\
\text { Precipitation: } 0.6 \pm 0.0 \mathrm{~mm}\end{array}$ \\
\hline
\end{tabular}

(Sigma-Aldrich, Steinheim, Germany) onto UFPs to increase their dimensions to the size that can be detected. UFP were measured daily between 8:30 a.m. to 5:30 p.m. which corresponded to the period that children were at preschools. Intake flow of $0.7 \mathrm{l} / \mathrm{min}$ was used and UFP logging interval was $60 \mathrm{~s}$ accor- dingly to previous studies (Diapouli et al., 2007;

Norback et al., 2011; Zhang and Zhu, 2012). Instruments were mounted onto supports so that air was sampled from a height of 0.8 to $1.1 \mathrm{~m}$ (to simulate children breathing zone). In each microenvironment, the particles counters were placed as far as possible from windows or doors, and from other probable sources of UFP (heating equipment, blackboards, printers, etc.) to minimize direct influence of any source; in canteens, the equipment was always positioned in the eating area, as far as possible from the serving area and kitchen where cooking was done. Over the sampling period, the cooking process included boiling, frying, and baking; each meal consisted of soup, main dish, and desert (typically fruit). All requirements to main- tain child safety were fulfilled. During sample collec- tion, a researcher was present to keep a record of classroom occupancy, ventilation systems (door and window positions), and potential source activities. In addition, teachers and staff were daily inquired regard- ing the occurrence of additional UFP sources and activities.

The UFP in ambient air were measured at preschool yards in a safe distance from areas with children's intense activity. The samplers were always positioned in open area avoiding any obstacles and barriers (trees, bushes walls, and fences) that could interfere with data collection. The equipment were mounted on support (sampling inlets height at $1.2 \mathrm{~m}$ above the ground) and protected from rain. The distance from the main street was 8-42 m.

Indoor temperature and relative humidity were measured by Testo mini data-logger $(174 \mathrm{H}$, Testo AG, Lenzkirch, Germany) which operated continuously with a logging interval of $10 \mathrm{~min}$. Information on out- door meteorological conditions, namely temperature (T), relative humidity $(\mathrm{RH})$, wind speed (WS), and precipitation $(\mathrm{P})$ were retrieved from the local meteorological stations and are summarized in Table 1.

Dose rate exposure analysis

Ultrafine particle dose rates from inhalation exposure were calculated using Equation 1 (Castro et al., 2009; Kalaiarasan et al., 2009):

\section{Dose rate $\partial \mathrm{P}^{1 / 4}{ }^{\partial \mathrm{BR}} \mathrm{wA}_{\mathrm{W}}=\mathrm{BWP} \times C_{\mathrm{WA}} \times \mathrm{OF} \times N$ ð1P}

where $D$ is the age-specific dose rate (particles/kg/day); $\mathrm{BR}_{\mathrm{WA}}$ is the age-specific weighted average breathing rate $(1 / \mathrm{min})$; $\mathrm{BW}$ is age-specific body weight $(\mathrm{kg}) ; C_{\mathrm{WA}}$ is the age-specific weighted average concentration (particles/l); OF is the occupancy factor (considered 1, as children kept their schedules and associated locations tightly); $N$ is the total time per day spent by agespecific children in the preschool (min/day). UFP dose rates were estimated for 3-5-year-old children that were the common age group in all three preschools (Table 1). The daily activity patterns of children were analyzed during each day. Locations in which the 
different activities happened during the day were identified. Total daily residence time of children spent in each microenvironment and the types of performed activities were registered. Each activity was characterized in terms of intensity level to assess the correspond- ing BR. An example of children timetable and activity patterns is shown in Table S4. As the information concerning the Portuguese population is not available, the age-specific factors were retrieved from US EPA data (U.S. EPA, 2011) considering the mixed population (both male and females). BW of $18.6 \mathrm{~kg}$ for 3-5-year- old children was used. The BR was selected as the followings: $4.3 \mathrm{l} / \mathrm{min}$ for rest or sleep; $4.5 \mathrm{l} / \mathrm{min}$ for sedentary or passive activities; $11.0 \mathrm{l} / \mathrm{min}$ for light intense activity, and $37.0 \mathrm{1} / \mathrm{min}$ for highly intense activities (running, etc.). $\mathrm{BR}_{\mathrm{WA}}$ was estimated then as weighted average, that is, considering the intensity of performed activities in each microenvironment and the amount of time spent there. The exposure doses were estimated using the UFP average concentrations (weighted by the real time that children spent in each microenviron- ment). Table S5 shows examples of UFP exposure doses calculation. For comparison, dose rates of inha- lation exposure to UFP were also estimated for the teachers and preschool staff (aged 25-64 years). Time schedules of teachers and preschool staff (i.e., period spent in each microenvironment) were considered the same as of children. Age-specific parameters $\mathrm{BR}_{\mathrm{WA}}(12 \mathrm{l} / \mathrm{min}$; i.e., light physical activity) and BW (77 kg) were used (U.S. EPA, 2011).

\section{Statistical methods}

$t$ Student's test was applied $(P<0.05$; two tailed $)$ to establish the statistical significance of the existing differences between the calculated averages. To assess the impact of outdoor UFP on indoor environments, the associations between indoor and outdoor UFP number concentrations were estimated by a bivariate linear regression, assuming a linear relationship. Spearman's rank correlation coefficient $(r s)(P<0.05)$ was also calculated to assess the influence of meteorological parameters on UFP number concentrations.

Results and discussion

UFP number levels

The UFP number concentrations measured in various microenvironments of the three preschools are pre- sented in Table 2, which shows the mean and ranges obtained for each microenvironment, as well as, the total UFP concentrations.

At all three preschools, canteens were the microenvironment with the highest levels of UFP particle num- ber concentrations. Examples of representative daily profiles of UFP concentrations in canteens are shown in Figure S1. During the morning, UFP concentrations were increasing. When meals were served, typically between 11:30 and 14:00 (i.e., the highest room occu- pancy), UFP reached the maximal levels. After that, cooking activities stopped, children and staff left the eating area (canteens were vacant for the rest of day), and consequently UFP levels continuously decreased. In all three preschools, the canteens were directly con- nected through serving areas (i.e., open spaces) to kitchens equipped with gas-fueled stoves. Therefore, cooking emissions could easily penetrate to the eating area and seem to represent the main emission source of UFP in these microenvironments (Buonanno et al., 2013b). The highest levels of UFP were found at can- teen of US1 (1.6 and 1.3 times higher than at US2 and RS1, respectively), which was the one with the highest number of enrolled students (Table 1). Similarly, low- est UFP levels were observed at US2 (preschool with the smallest number of enrolled students).

In all three preschools, classrooms were the microenvironment with lower UFP number concentrations. This finding is somewhat reassuring, given that it is the microenvironment where children spend most of their

Table2 Ultrafine particle number concentrations at the three characterized pre-schools (particle $/ \mathrm{cm}^{3}$ )

\begin{tabular}{|c|c|c|c|c|c|c|}
\hline & \multicolumn{2}{|c|}{ Urban pre-school 1} & \multicolumn{2}{|c|}{ Urban pre-school 2} & \multicolumn{2}{|c|}{ Rural pre-school1 } \\
\hline & Mean & Range & Mean & Range & Mean & Range \\
\hline \multicolumn{7}{|c|}{ Microenvironment } \\
\hline Classrooms $^{\mathrm{a}}$ & $9.31910^{3}$ & $2.51910^{3}-1.13910^{5}$ & $1.13910^{4}$ & $3.01910^{3}-4.19910^{4}$ & $7.14910^{3}$ & $2.24910^{3}-4.50910^{4}$ \\
\hline 0Floor & $8.58910^{3}$ & $2.51910^{3}-1.04910^{5}$ & $1.16910^{4}$ & $3.01910^{3}-4.19910^{4}$ & $7.61910^{3}$ & $2.24910^{3}-4.50910^{4}$ \\
\hline 1 Floor A & $8.80910^{3}$ & $3.14910^{3}-1.13910^{5}$ & $1.24910^{4}$ & $5.87910^{3}-2.25910^{4}$ & $5.91910^{3}$ & $2.53910^{3}-1.60910^{4}$ \\
\hline 1 Floor B & $1.06910^{4}$ & $4.23910^{3}-2.92910^{4}$ & $8.86910^{3}$ & $3.64910^{3}-2.79910^{4}$ & n.a. & n.a. \\
\hline Canteen & $5.17910^{4}$ & $9.28910^{3}-1.73910^{5}$ & $3.28910^{4}$ & $1.05910^{4}-2.48910^{5}$ & $4.09910^{4}$ & $7.18910^{3}-1.38910^{5}$ \\
\hline Gymnasium & n.a. ${ }^{\text {b }}$ & n.a. & $9.72910^{3}$ & $5.46910^{3}-1.71910^{4}$ & n.a. & n.a. \\
\hline Playroom & $1.70910^{4}$ & $5.28910^{3}-1.93910^{5}$ & n.a. & n.a. & n.a. & n.a. \\
\hline Total & $1.82910^{4}$ & $2.51910^{3}-1.93910^{5}$ & $1.32910^{4}$ & $3.01910^{3}-2.48910^{4}$ & $1.15910^{4}$ & $2.24910^{3}-1.38910^{5}$ \\
\hline
\end{tabular}

abased on the measurements of all the classrooms ( 0 and 1 floor A, B).

b.a., not available (i.e., inexistent microenvironment). 

school time. Of the three preschools, classrooms at RS1 exhibited the lowest levels of UFP which might be due to the lack of urbanization and/or anthropogenic sources of this site. At US1 and US2, the concentra- tions of UFP in classrooms were, approximately 30 and $60 \%$ higher, respectively, than at $\mathrm{RS} 1$; the differ- ences between the means of UFP in classrooms of rural and urban preschools were statistically significant $(P<0.05)$. Specifically, the highest mean of UFP was found at classrooms of US2, probably due to the room organizations, sizes, and characteristics; classrooms at US2 were the smallest and most cluttered (Table S2). Furthermore, within each preschool, the levels of UFP were significantly different in classrooms on 0 and 1 floor $(P<0.05)$. In addition, it is necessary to point out that temporarily ( 3 up to $120 \mathrm{~min}$ ), UFP concen- trations reached high levels in classrooms of all three preschools. These increases were associated with spe- cific indoor sources registered in the classrooms of the three preschools which included children activities dur- ing classes (i.e., painting, sculpturing, and other arts and crafts activities), combustion sources (candles on birthday cake), and classroom cleaning (dusting and

wood polishing) (Morawska et al., 2009). Ventilation by open windows and consequent penetration of UFP

from outdoors was also identified as an important source of UFP indoors. This specific source was identi-

fied based on the comparisons of the daily activity observations (a research and/or teacher registered open windows) and temporarily increases of UFP. The highest maximal levels of UFP were measured at US1 (up to 13 times higher than estimated mean) during candle burning on birthday cake (Figure S2) and during activ- ity that included clay grinding (Figure 1a).

Gymnasium and playroom exist only at one pre- school (US2 and US1, respectively). The levels of UFP in gymnasium were similar to those at classrooms of the respective preschool. Playroom exhibited approximately twice higher levels of UFP number concentra-

tions than the classrooms. This room was used for multiple purposes: waiting area to drop off and pick up of children (before, during, and after school hours), for extra-curricular activities, to eat snacks, or even as classroom or gymnasium for 3-5-year-old children. Consequently, levels of UFP varied greatly and concentration profiles exhibited considerable variances every day. Among the identified sources were chil- dren's physical activities (dancing and exercising); painting and cleaning; and use of chemical products and ventilations (opened windows and doors).

Total mean UFP concentrations were determined using all measured data for each preschool despite the inexistence of some microenvironments in some preschools (gymnasium, playroom), association with highly specific indoor sources (canteen), and small occupancy times. The highest total mean levels of UFP were found at US1 being 1.4 and 1.6 higher than at
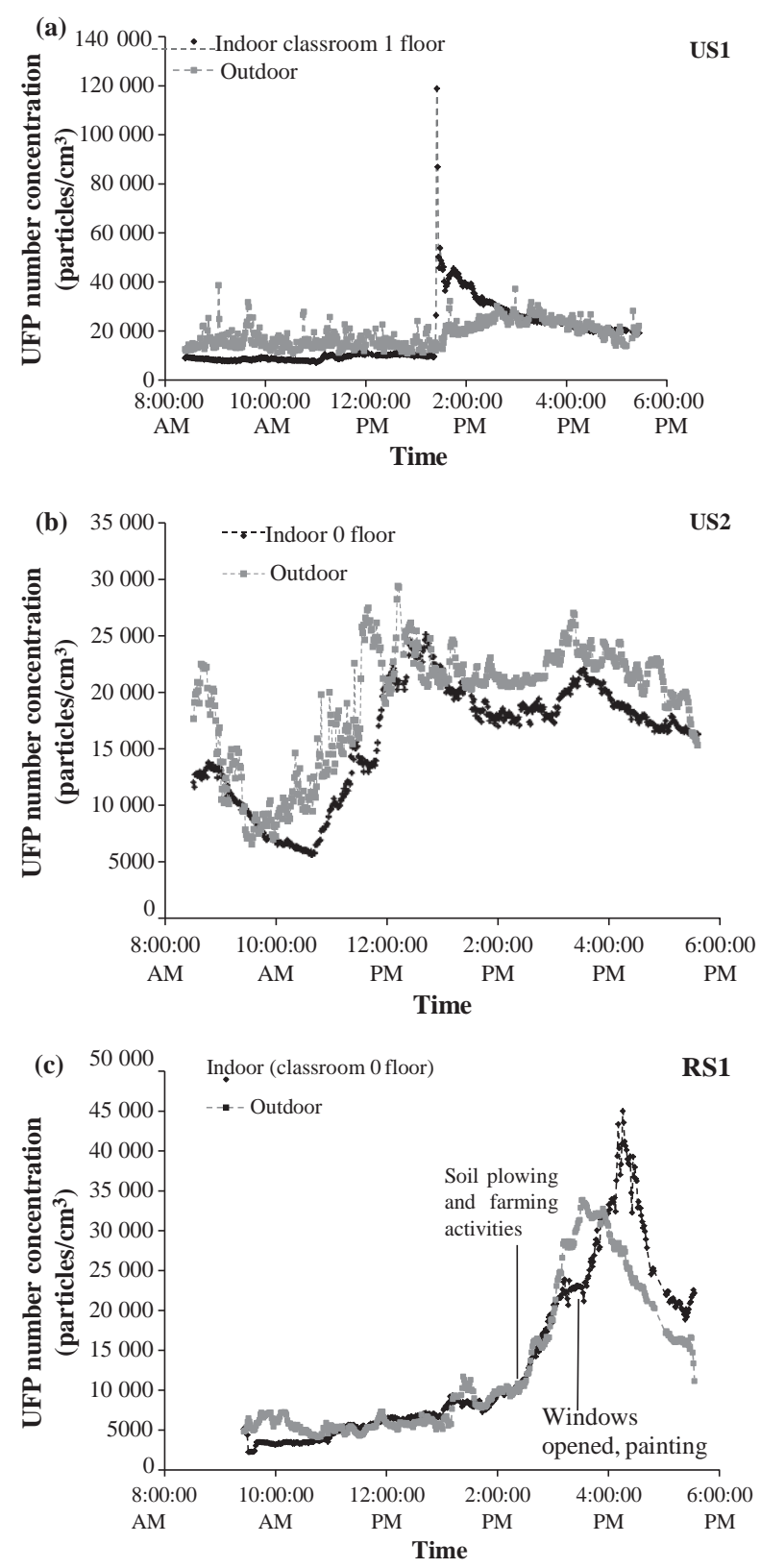

Fig. 1 Examples of indoor and outdoor ultrafine particle (UFP) concentrations profiles at three pre-schools: (a, b) urban (US1 and US2), (c) rural (RS1). At urban pre-school US1, the increase of UFP was associated with clay material that was being grinded by teacher for afternoon classes. Concentration trend of UFP at urban pre-school US2 shows the similarity of indoor and outdoor profiles

US2 and RS1, respectively; the results showed that the total means of UFP at urban preschools were statistically different $(P<0.05)$ than at rural one. Nevertheless, these findings need to be interpreted with care once UFP were measured at three preschools consequently. The comparisons of UFP particles with other studies are shown in Table 3. The total levels of UFP in the three characterized Portuguese preschools were similar to those of Southern Europe, namely Italy (Buonanno et al., 2012, 2013a,b), Greece (Diapouli 
Table 3 Ultrafine particle at schools: summary of existent studies

\begin{tabular}{|c|c|c|c|c|c|}
\hline Continent & Country & $\begin{array}{l}\text { Mean (range) } \\
\left(\text { particle/cm } \mathrm{cm}^{3}\right)\end{array}$ & $\begin{array}{l}\text { Particle } \\
\text { fraction }\end{array}$ & Study design & Reference \\
\hline \multirow[t]{7}{*}{ Europe } & Portugal & $\begin{array}{l}14.9-19.3910^{3} \\
\left(2.23910^{3}-1.93910^{5}\right)\end{array}$ & $0.02-11 \mathrm{~m}$ & & This study \\
\hline & Germany & $6.5910^{3}\left(2.6-12.1910^{3}\right)$ & $10-487 \mathrm{~nm}$ & $\begin{array}{l}64 \text { primary and secondary schools; } 36 \text { classrooms; Sampling both in } \\
\text { winter and summer; Sample collection during } 1 \text { day for } 5 \mathrm{~h} \text {; }\end{array}$ & Fromme et al. (2007) \\
\hline & Greece & $24910^{3}$ (n.r. $-52910^{3}$ ) & $0.01-1 \mathbf{1 m}$ & $\begin{array}{l}7 \text { primary schools; Different indoor microenvironments; } \\
\text { Samples collected in } 2 \text { winter periods; } 8 \text { h sample } \\
\text { collection ( } 8: 00 \text { to } 16: 00) \text {; }\end{array}$ & Diapouli et al. $(2007,2008)$ \\
\hline & Denmark & $1.6910^{3 \mathrm{a}}\left(2.2-36.4910^{3}\right)$ & n.a. & 150 day-care facilities (children $1-5$ years old) & Clausen et al. (2012) \\
\hline & Italy & $12-40910^{3}$ (n.r.) & $10-300 \mathrm{~nm}$ & $\begin{array}{l}3 \text { schools ( } 2 \text { primary and } 1 \text { secondary); Sample collection for } \\
2 \text { days; Personal exposure assessment: } 100 \text { children } \\
\text { aged } 8-11 \text { years; Various } \\
\text { microenvironments/activities; }\end{array}$ & Buonanno et al. (2012) \\
\hline & Italy & $19.5-20.4910^{3}$ (n.a.) & $<100 \mathrm{~nm}$ & $\begin{array}{l}3 \text { schools; } 2-3 \text { classrooms in each school; } 2 \text { weeks } \\
\text { sampling in each schools; Sample collection during } \\
\text { school hours ( } 8: 30 \text { to } 13: 30 \text { or to } 16: 30)\end{array}$ & Buonanno et al. (2013a) \\
\hline & Sweden & $0.7-4.4910^{3}$ (n.a.) & $0.01-1 \mathbf{1 m}$ & $\begin{array}{l}1 \text { elementary school; Total of } 61 \text { classrooms; Sampling repeatedly during } 3 \\
\text { weeks; } 3 \text { h sample collection; }\end{array}$ & Nabfacket al. (2011) \\
\hline \multirow[t]{3}{*}{$\begin{array}{l}\text { North } \\
\text { America }\end{array}$} & Canada & $\begin{array}{l}5.4910^{3}\left(1.1-10.4910^{3}\right) \\
4.6910^{3}\left(1.0-11.4910^{3}\right)\end{array}$ & $0.02-11 \mathrm{~m}$ & $\begin{array}{l}2 \text { schools: } 1 \text { elementary } 1 \text { secondary; } 37 \text { classrooms; Sampling during three } \\
\text { 1-week periods; Sample collection for } 7 \text { h }(8: 30 \text { to } 15: 30) \text {; }\end{array}$ & Weichenthal et al. (2008) \\
\hline & California, USA & $6.9910^{3}\left(2.1-21.7910^{3}\right)$ & $<100 \mathrm{~nm}$ & 1 school; 6 classrooms; Samples collected during 18 days; & Mullen et al. (2011) \\
\hline & Texas, USA & $0.9-3.8910^{3}\left(0.6-29.3910^{3}\right)$ & $7.6-100 \mathrm{~nm}$ & $\begin{array}{l}\text { schools; Various microenvironments; Sample collection during } \\
\text { 3-8 days in each school; }\end{array}$ & Zhang and Zhu (2012) \\
\hline \multirow[t]{3}{*}{ Australia } & & $12.1-16.9910^{3 a}$ (n.a.) & $0.01-1 \mathbf{1 m}$ & $\begin{array}{l}6 \text { primary schools ( } 3 \text { new and } 3 \text { old); } 4-6 \text { classrooms in each school; } \\
8 \text { h sample collection; }\end{array}$ & Rumchev et al. (2007) \\
\hline & & $5.2910^{3}$ (n.a. $-140910^{3}$ ) & $<100 \mathrm{~nm}$ & $\begin{array}{l}1 \text { primary school; } 3 \text { classrooms; Samples collected in } 60 \text { days ( } 2 \text { winter } \\
\text { periods); } 23 \text { h sample period; }\end{array}$ & Morawska et al. (2009) \\
\hline & & $3.19910^{3}$ (n.a. $-110910^{3}$ ) & $<100 \mathrm{~nm}$ & $\begin{array}{l}1 \text { primary school; } 1 \text { classroom, } 1 \text { preschool center (children }<6 \text { years } \\
\text { old); Sample collection for } 10 \text { days continuously; }\end{array}$ & Guo et al. (2010) \\
\hline Asia & South Korea & $18.2910^{3}\left(3.7-52.8910^{3}\right)$ & $0.02-1 \mathbf{1 m}$ & 34 schools; Sample collection for 7 day periods for each school; & Kim et al. (2011) \\
\hline
\end{tabular}

et al., 2008), Australia (Rumchev et al., 2007), and South Korea (Kim et al., 2011). Other studies from Europe (Germany, Sweden, and France), North Amer- ica (USA and Canada), and Australia reported levels of UFP in preschools 3-17 times lower than in the present work. Seasonal influences, meteorological con- ditions, level of urbanization, and overall development of area where the preschools were located could account for some of these differences (Morawska et al., 2009; WHO, 2006). Other study design (sampling per- iod, duration, number of preschools) could also con- tribute to the obtained differences (Morawska et al., 2013). In addition, differences in the measured particle range, especially in terms of lower cut-off size could also account for some of the existent results (Kumar et al., 2010). Finally, with exception to the study by Zhang and Zhu (2012) and Diapouli et al. (2007, 2008), all other works assessed UFP only in class- rooms. The total concentrations in the present study also considered various other microenvironments of preschools. In that regard, canteens were especially rel- evant indoor places (Table 2). The levels of UFP in canteens were 3-6 times higher than in classrooms which consequently contributed to higher overall aver- age in the studied schools; absence of these special mic- roenvironments in other studies could also justify the differences between UFP levels.

Indoor/outdoor UFP

The statistical parameters of average UFP number concentrations outdoors (i.e., preschool yard) and indoors (in classrooms) at three preschools are pre- sented in Figure 2. Examples of UFP concentration profiles in ambient air and in the classrooms of three preschools are shown at Figure 1a-c. At the urban pre- schools, the mean of UFP concentrations in outdoor air was $1.72910^{4}$ and $1.21910^{4}$ particles/ $\mathrm{cm}^{3}$ at US1 and US2, respectively. The statistical analysis of these results indicated that they are significantly differ- ent $(P<0.05)$. The previously conducted study has shown that emissions from vehicular traffic are the main pollution source to ambient air in this area (Sle- zakova et al., 2013) and the higher traffic density nearby US1 (Table 1) may account for some of the observed differences. At preschool situated in rural area, mean concentration UFP in ambient air (1.02 $910^{4}$ particles $\left./ \mathrm{cm}^{3}\right)$ was significantly lower $(P<0.05)$ in comparisons with urban ones, probably due to much lower traffic density and lower influence 


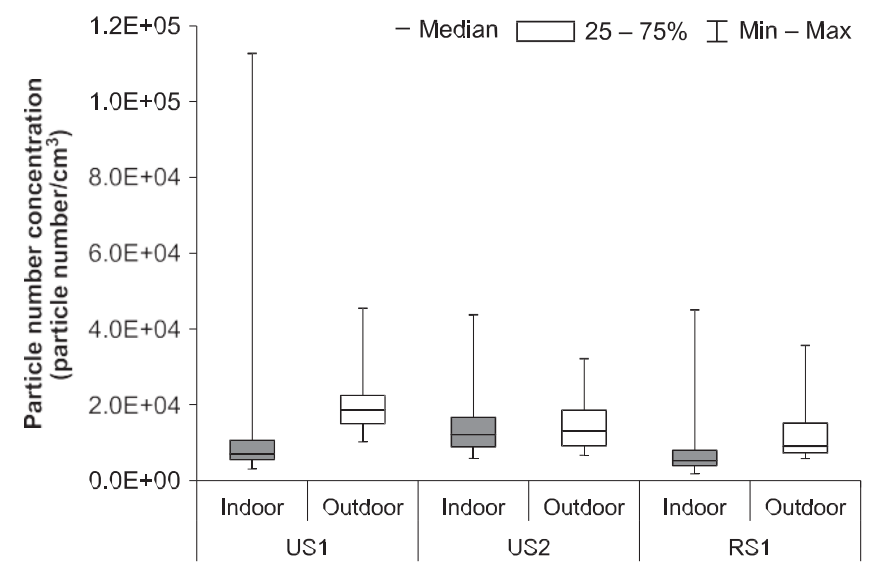

Fig. 2 Average ultrafine particle number concentrations at two urban (US1 and US2) and one rural (RS1) pre-schools: minimum and maximum values, median, 25 th, and 75 th percentile

of anthropogenic sources (Table 1); the mean of UFP was at RS1 70 and 20\% lower than at US1 and US2, respectively. Natural sources of UFP, namely atmospheric formations and emissions from vegetation (plantations, forests) (Diapouli et al., 2007; Morawska et al., 2008), that surrounded the vicinity of rural preschool might account for these levels. It is necessary to repeat that UFP at three schools were sampled during different dates, which could also account for some of the observed differences. Furthermore, during the UFP sampling at RS1, soil plowing and other farming activities were registered during 3 days at several planta- tions which might contribute to observed levels of UFP in ambient air (Figure 1c). In addition, the results in Figure 2 show that overall levels of UFP in the classrooms of RS1 were lower than in ambient air; this pattern was also observed in the urban preschools. On the contrary, maximal levels of UFP outdoors were

lower than indoors ones. These occurrences were due to the presence of specific indoor sources (combustion and indoor activities) in the classrooms of three pre-schools that caused during relatively short periods of time high levels of UFP, especially high maxima of UFP were observed at US1.

To further evaluate the influence of outdoor emissions to indoor air quality, $\mathrm{I} / \mathrm{O}$ ratios between the concentrations of UFP in classrooms and in outdoor air were calculated. At US1, the values of I/O ratios ranged between 0.13 and 9.77 (mean of 0.54), whereas it was contribution of UFP from indoor sources with RS1 being the least influenced by those sources.

The influence of air quality to indoors was also analyzed by bivariate linear regression, assuming a linear relationship (Figure 3a-c). It is possible to observe that at US2 and RS1 (Figure 3b-c), indoor and outdoor UFP were relatively well associated (with $\mathrm{R}^{2}$ of 0.82
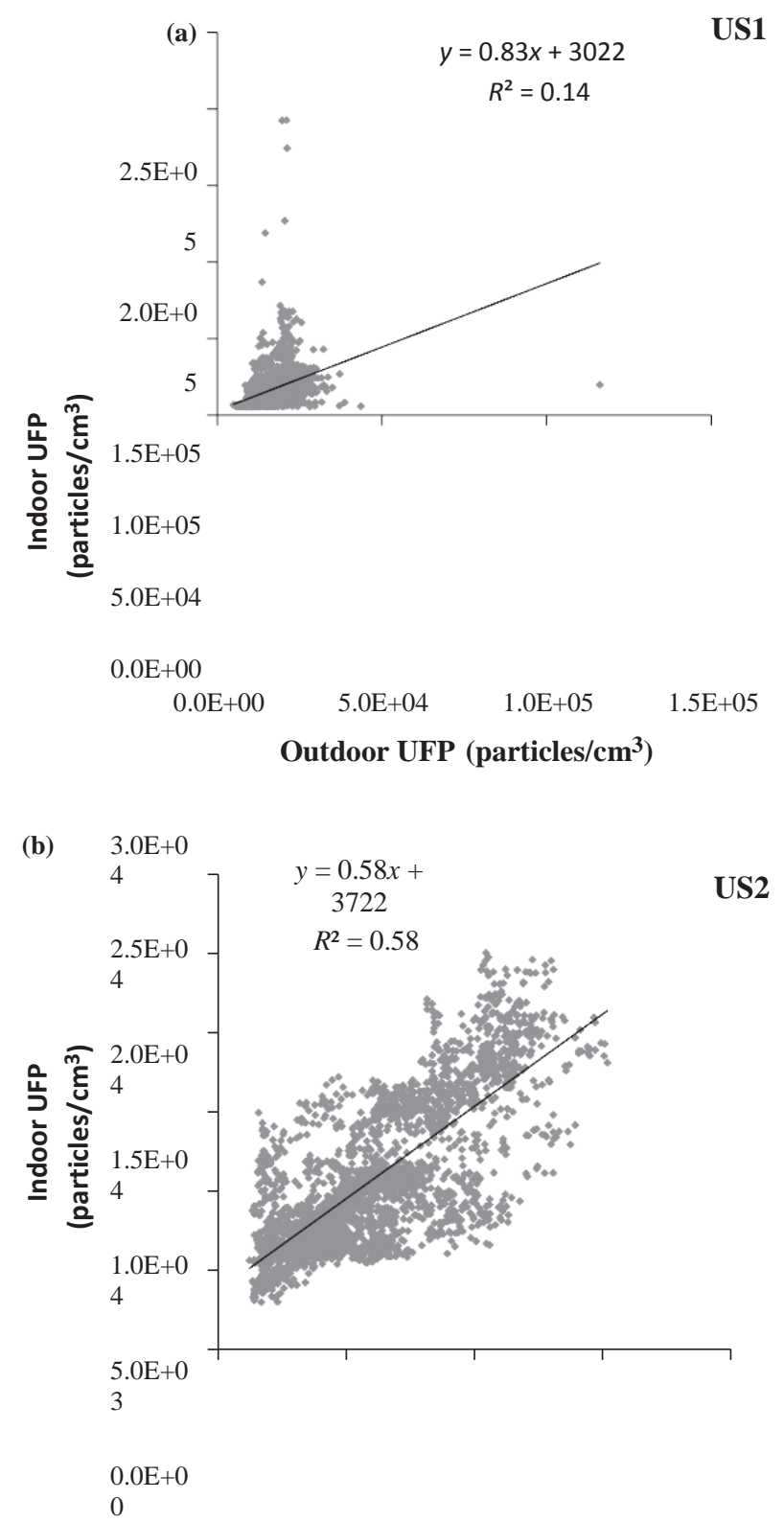

US2

b $\quad 4.72$ at US2 (mean of 0.93 ); the respective ratio range was et between 0.35 and 2.59 at RS1 (mean of 0.70). Overall, the w mean I/O ratios were similar to those previously reported ee (Buonanno et al., 2013a; Weichenthal et al., 2008). At all $\mathrm{n}$ three prescho- ols, the mean values of $\mathrm{I} / \mathrm{O}$ ratios were lower 0 . than 1 which indicates that outdoor emissions may 3 influence 

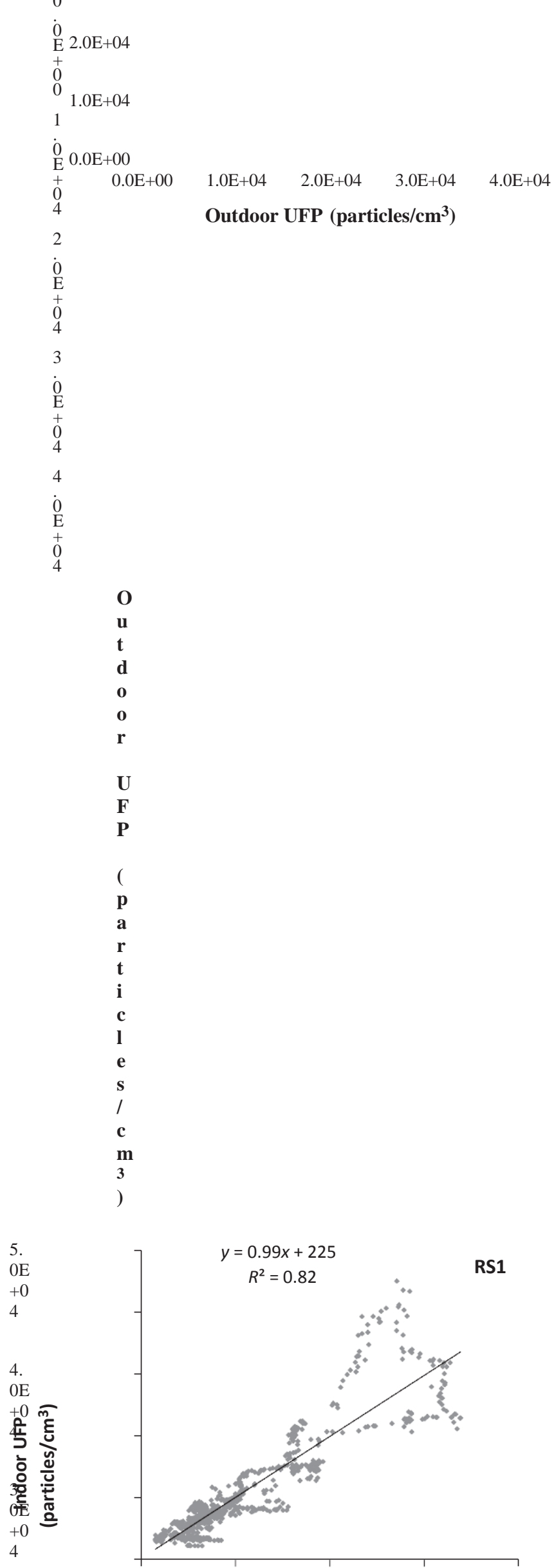
UFP levels in classrooms. It is necessary to point out that high values of maximal I/O ratios (9.77 for US1, 4.72 for US2, and 2.59 for RS1) probably indicate
Fig. 3 Correlation of indoor and outdoor ultrafine particle concentrations at three pre-schools: (a, b) urban (US1 and US2), (c) rural (RS1) 
and 0.58 , respectively) which further supports the previous findings concerning the impacts of outdoor air. At US1 (Figure 3a), the linear regression between the indoor and outdoor UFP concentrations was poorer $\left(\mathrm{R}^{2}\right.$ of 0.14$)$ due to the much high variance of indoor UFP levels (temporal contribution from specific indoor sources).

Influence of meteorological parameters

The potential influence of indoor ( $\mathrm{T}$ and $\mathrm{RH})$ and ambient parameters (T, SR, RH, and WS) on indoor and outdoor UFP number concentrations were ana- lyzed through the calculation of Spearman's correla- tion coefficient (Table 4). For the analysis of indoor UFP, classrooms were the only considered indoor microenvironment (due to their existence in all three preschools); canteens were not considered to avoid the specificity of cooking emissions. Positive correlations were found between $\mathrm{T}$ and UFP number concentra- tions both indoors and outdoors. In addition, SR was positively correlated with outdoor UFP number con- centrations, so the positive correlation between UFP, SR, and outdoor $\mathrm{T}$ might be due to photochemical activity, leading to an increase in the concentration of UFP (Park et al., 2008). Evaluating different fractions of UFPs, Wang et al. (2010) reported that nucleation mode particles $(4-10,10-30 \mathrm{~nm}$ in diameter) are more affected by $\mathrm{SR}$ and $\mathrm{T}$, whereas Aitken mode fractions $(30-50$ and $50-70 \mathrm{~nm})$ corresponded closely to $\mathrm{RH}$. The results of this study are somewhat inconclusive concerning RH. Whereas outdoor UFP and RH were inversely correlated at all three preschools, the correla- tion coefficients for indoors were only significant for US2. Finally, WS showed significant inverse correla- tions with outdoor UFP as reported also by Wang et al. (2011). In agreement with these findings, Wei- chenthal et al. (2008) also reported inverse correlations of WS and UFP number concentration. High WS might influence the observed UFP number concentration profiles during the sampling, promoting a higher instantaneous variability and oscillation of UFP num- ber concentrations. It is necessary to point out that although the obtained results appear to be consistent

Table 4 Spearman's correlation coefficients between ultrafine particle number concentra-

tion, indoor (T, RH) and outdoor meteorological parameters (T, RH, WS, SR) at two urban (US1, US2) and one rural (RS1) pre-schools

\begin{tabular}{|c|c|c|c|c|c|c|}
\hline & \multicolumn{2}{|c|}{ Urban pre-school 1} & \multicolumn{2}{|c|}{ Urban pre-school 2} & \multicolumn{2}{|c|}{ Rural pre-school1 } \\
\hline & Indoor & Outdoor & Indoor & Outdoor & Indoor & Outdoor \\
\hline $\mathrm{T}\left({ }^{\circ} \mathrm{C}\right)$ & 0.423 & 0.119 & 0.205 & 0.598 & 0.254 & 0.473 \\
\hline RH (\%) & -0.029 & -0.430 & -0.308 & -0.478 & -0.070 & -0.630 \\
\hline WS (km/h) & n.a. & -0.136 & n.a. & -0.171 & n.a. & -0.301 \\
\hline $\mathrm{SR}\left(\mathrm{W} / \mathrm{m}^{2}\right)$ & n.a. & 0.108 & n.a. & 0.178 & n.a. & 0.581 \\
\hline
\end{tabular}

Values in bold are statistically significant for $P<0.05$;

n.a., not available. with the finding of previous studies, the observed associations between the meteorological parameters and UFP may be influenced by unmeasured confounding factors between these parameters.

Exposure dose analysis

The inhalation exposure dose rates of UFP were estimated for 3-5-year-old children that were the common age group at all three preschools (Table 5). At both urban preschools, 3-5-year-old children were divided into the classes according to their age (although differ- ently at both preschools). These age-classes had differ- ent daily schedules and activities. For example, the youngest rested (i.e., napped) after lunch for $2-2.5 \mathrm{~h}$, whereas older children spent daily more times out- doors $(0.75-1.75 \mathrm{~h})$. The organization structure of the rural preschool was simpler and all children between 3-5 years were joined to the same class, and they all had the same daily schedule and/or activity patterns. The highest exposure doses of UFP were found for children of US1. At both urban preschools, classrooms were the microenvironment where children spend majority of their school time (approximately $70-75 \%$ for young ones and $57-70 \%$ for older ones). As previ- ously shown (Table 2), overall levels of UFP in class- rooms were the highest at US2. Still, for all age categories, the exposure doses of UFP were at US1 1.5 times higher than at US2, mostly due to the exposure to higher levels of UFP in canteen of US1. Although children spend in canteens rather limited period of school time (18 and 19\% of their school time at US1 and US2, respectively), the contribution to the total exposure of UFP is relevant. In addition, these findings clearly show that when assessing children exposure to UFP in preschools, all potential microenvironments should beconsidered.

The total estimated dose rates between the different age-groups at the two urban preschools were also compared. The results in Table 5 clearly show that at both urban schools exposure doses of UFP were approximately 1.5 times for older children (namely 5 years old at US1 and 4-5 years old at US2) than for younger

Table 5 Total age-specific dose rates of ultrafine particle at two urban (US1 and US2) and one rural (RS1) pre-schools

\begin{tabular}{|c|c|c|c|c|c|}
\hline & \multicolumn{2}{|l|}{ US1 } & \multicolumn{2}{|l|}{ US2 } & \multirow{2}{*}{$\frac{\mathrm{RS} 1}{3-5 \text { years }}$} \\
\hline & $3-4$ years & 5 years & 3 years & 4-5 years & \\
\hline \multicolumn{6}{|c|}{ Dose rate (particles $/ \mathrm{kg} /$ day) Children } \\
\hline Mean & $4.60910^{9}$ & $7.52910^{9}$ & $2.94910^{9}$ & $4.48910^{9}$ & $4.50910^{9}$ \\
\hline Min & $1.06910^{9}$ & $1.84910^{9}$ & $1.04910^{9}$ & $1.37910^{9}$ & $9.50910^{8}$ \\
\hline Max & $2.95910^{10}$ & $4.20910^{10}$ & $1.48910^{10}$ & $2.51910^{10}$ & $1.92910^{10}$ \\
\hline \multicolumn{6}{|l|}{ Adults } \\
\hline Mean & $1.12910^{9}$ & $1.25910^{9}$ & $8.17910^{8}$ & $1.01910^{9}$ & $7.01910^{8}$ \\
\hline Min & $2.60910^{8}$ & $3.05910^{8}$ & $2.90910^{8}$ & $2.87910^{8}$ & $1.48910^{8}$ \\
\hline Max & $7.21910^{9}$ & $6.95910^{9}$ & $4.11910^{9}$ & $5.25910^{9}$ & $3.00910^{9}$ \\
\hline
\end{tabular}


ones (3-4 years and 3 years at US1 and US2, respectively). At each urban preschool-older children spent approximately twice more outdoors (25 and $7 \%$ of their school time at US1 and US2, respectively) than young ones (11\% at US1 and 4\% at US2). Older chil- dren also performed more frequently physical activities such as exercising, running, and playing (both indoors and outdoors) which were associated with the highest breathing rates and consequently led to higher inhala- tion doses of UFP. In agreement with these findings, the dose rates due to outdoor exposure contributed for older children 48 and $27 \%$ of the total UFP school dose at US1 and US2, respectively, whereas for youn- ger ones, it was $33 \%$ at US1 and $19 \%$ at US2. In addi- tion, UFP dose rates due to outdoor exposure were higher at US1 where children spent more time out- doors. On the contrary, young children spend more time indoors where overall UFP levels were lower that outdoors which might cause the lower total dose rates of UFP (Table 5). In addition, at both preschools, the younger children napped (in the classrooms) after the lunch which was an activity with the lowest breathing rates.

The estimated total dose rates of UFP at RS1 were similar to those of US1 (3-4 years old) and US2 (4- 5 years old). These exposure doses were higher than expected (in a view of lower indoor UFP concentrations at this preschool; Table 2) probably due to the consider- ably longer period spent outdoors. At rural preschool, children spent approximately $40 \%$ of their school times outdoors and the UFP dose rates due outdoor exposure accounted for $60 \%$ of the total school exposure, thus being at RS1 the highest proportion of all three prescho- ols. These findings show that daily activity patterns at the respective schools influenced significantly the over- all child exposure dose rates to UFP.

Finally, to better understand the magnitude of UFP exposures at the three characterized preschools, the dose rates of children were compared with those of adults. The results in Table 5 show that exposure doses for 3 5 -year-old children in the respective pre- schools were 3.6 to 6.4 times higher than those of adults. Considering the high susceptibility of young children, these results demonstrate that preschools are an important environment for child overall parti- cles exposure. Finally, the information on the expo- sure to UFP in children is limited and therefore the findings on UFP dose rates of 3-5-year-old children obtained within this work could not be compared with other studies.

\section{Conclusions}

This study fills a gap providing information on the UFP levels and exposure doses in Portuguese prescho- ols. The results demonstrated that levels of UFP in var- ious microenvironments of preschools differed significantly with the lowest levels of UFP observed in the classrooms (where children spend $70-75 \%$ of their school time) and the highest ones found in canteens. Therefore, future population-based studies focusing on the health effects of airborne pollutants need to account for the exposures occurring in these different microenvironments to obtain a representation of child's overall preschool exposure profiles. Further- more, the results of the present study suggested that children attending urban preschools are potentially exposed to higher concentrations of UFP in air, mainly due to the contribution of outdoor traffic-related sources and extra cooking activities (usually due to higher number of enrolled students). Nevertheless, the daily activity patterns at the respective schools influ- enced significantly the overall child exposure dose rates to UFP.

Children represent one of the most vulnerable groups in society. However, in comparison with adults, the exposure doses for 3-5-year-old children in the respective preschools were 4 to 6 times higher than those of adult. Therefore, to provide information for the protection of public health, the future work should focus on the individual exposure of children.

\section{Acknowledgments}

This work was supported by Funda_ $\sim$ ao para $\mathrm{Ci}^{\wedge}$ encia e Tecnologia through fellowship SFRH/BPD/65722/ 2009 and by the IJUP project PP_IJUP2011 121. It also received financial support from the European Union (FEDER funds through COMPETE) and National Funds (Funda_c ao para a Ci^encia e Tecnologia) through projects PEst-C/EQB/UI0511/2013 and PestC/EQB/LA0006/2013.

\section{Supporting Information}

Additional Supporting Information may be found in the online version of this article:

Table S1. Characteristics of the studied indoor microenvironments at the urban school 1 (US1).

Table S2. Characteristics of the studied indoor microenvironments at the urban school 2 (US2).

Table S3. Characteristics of the studied indoor microenvironments at the rural school(RS1).

Table S4. Timetable and child activity patterns: an example for 3-4-year-old children at US1.

Table S5. Calculation of the UFP dose rates: an example for 3-4-year-old children at US1.

Figure S1. Example of daily profiles of UFP concentrations at the canteens of two urban (US1 and US2) and one rural (RS1) school.

Figure S2. Comparisons of concentrations profiles of UFP at two classrooms of urban school 1 (US1). 


\section{References}

Bhangar, S., Mullen, N.A., Hering, S.V., Kreisberg, N.M. and Nazaroff, W.W. (2011) Ultrafine particle concentrations and exposures in seven residences in northern California, Indoor Air, 21, 132144.

Brunekreef, B., Beelen, R., Hoek, G., Scho- uten, L., Bausch-Goldbohm, S., Fischer, P., Armstrong, B., Hughes, E., Jerrett,

M. and van den Brandt, P. (2009) Effects of long-term exposure to traffic- related air pollution on respiratory and cardiovascular mortality in the Netherlands: the NLCS-AIR study, Res. Rep. Health Eff. Inst., 139, 5-71; discussion 73-89.

Buonanno, G., Marini, S., Morawska, L. and Fuoco, F.C. (2012) Individual dose and exposure of Italian children to ultrafine particles, Sci. Total Environ.,438, 271-277.

Buonanno, G., Fuoco, F.C., Morawska, L. and Stabile, L. (2013a) Airborne particle concentrations at schools measured at different spatial scales, Atmos. Environ., 67, 38-45.

Buonanno, G., Stabile, L., Morawska, L. and Russi, A. (2013b) Children exposure assessment to ultrafine particles and black carbon: the role of transport and cooking activities, Atmos. Environ., 79, 53-58.

Burtscher, H. and Schtepp, K. (2012) The occurrence of ultrafine particles in the specific environment of children, Paediatr. Respir. Rev., 13, 89-94.

Cassee, F.R., H'eroux, M.-E., Gerlofs-Nijland, M.E. and Kelly, F.J. (2013) Particulate matter beyond mass: recent health evidence on the role of fractions, chemical constituents and sources of emission, Inhal. Toxicol., 25, 802-812.

Castro, D., Slezakova, K., Delerue-Matos, C., Alvim-Ferraz, M.D.C., Morais, S. and Pereira, M.D.C. (2009) Polycyclic aromatic hydrocarbons in gas and particulate phases of indoor environments influenced by tobacco smoke: levels, phase distributions, and health risks, Atmos. Environ., 45, 1799-1808.

Clausen, G., Høst, A., Toftum, J., Bek6, G., Weschler, C., Callesen, M., Buhl, S., Ladegaard, M.B., Langer, S., Andersen, B., Sundell, J., Bornehag, C.G. and Sigsgaard, T. (2012) Children's health and its association with indoor environments in Danish homes and daycare centres methods, Indoor Air, 22, 467-475.

Diapouli, E., Chaloulakou, A. and Spyrellis, N. (2007) Levels of ultrafine particles in different microenvironments-implicationsto children exposure, Sci. Total Environ.,388, 128-136.

Diapouli, E., Chaloulakou, A., Mihalopoulos, N. and Spyrellis, N. (2008) Indoor and outdoor PM mass and number con- centrations at schools in the Athens area, Environ. Monit. Assess., 136, 13-20.

Donaldson, K., Stone, V., Clouter, A., Renwick, L. and MacNee, W. (2001) Ultrafine particles, Occup. Environ. Med., 58, 211-216.

Ferreira, A.J., Cemlyn-Jones, J. and Robalo Cordeiro, C. (2013) Nanoparticles, nanotechnology and pulmonary nanotoxicology, Rev. Port. Pnemol., 19, 28-37.

Fromme, H., Twardella, D., Dietrich, S., Heitmann, D., Schierl, R., Liebl, B. and Riden, H. (2007) Particulate mat- ter in the indoor air of classroomsexploratory results from Munich and surrounding area, Atmos. Environ., 41, 854-866.

Guo, H., Morawska, L., He, C., Zhang, Y.L., Ayoko, G. and Cao, M. (2010) Characterization of particle number concentrations and PM2.5 in a school: influence of outdoor air pollution on indoor air, Environ. Sci. Pollut. Res., 17, 12681278.

Kalaiarasan, M.R., Balasubramanian, K.W.D. and Cheong and Tham, K.W. (2009) Traffic-generated airborne parti- cles in naturally ventilated multi-storey residential buildings of Singapore: verti- cal distribution and potential health risks, Build. Environ., 44, 1493-1500.

Kim, J.-L., Elfman, L., Wieslander, G., Ferm, M., Toren, K. and Norbfack, D. (2011) Respiratory health among Korean pupils in relation to home, school and outdoor environment, J. Korean Med. Sci., 26, 166-173.

Kumar, P., Robins, A., Vardoulakis, S. and Britter, R. (2010) A review of the characteristics of nanoparticles in the urban atmosphere and the prospects for developing regulatory controls, Atmos. Environ., 44, 5035-5052.

Kumar, P., Robins, A., Vardoulakis, S. and Quincey, P.(2011) Technical challenges in tackling regulatory concerns for urban atmospheric nanoparticles, Particuology, 9, 566-571.

Kumar, S., Verma, M.K. and Srivastava, A.K. (2013) Ultrafine particles in urban ambient air and their health perspectives, Rev. Environ. Health, 28, 117-128.

Kumar, P., Morawska, L., Birmili, W., Paasonen, P., Hu, M., Kulmala, M., Harrison, R.M., Norford, L. and Britter, R. (2014) Ultrafine particles in cities, Environ. Int., 66, 1-10.

Long, C.M., Suh, H.H. and Koutrakis, P. (2000) Characterization of indoor particle sources using continuous mass and size monitors, J. Air Waste Manag. Assoc., 50, 1236-1250.

Morawska, L., He, C.R., Hitchins, J., Meng- ersen, K. and Gilbert, D. (2003) Charac- teristics of particle number and mass concentrations in residential houses in
Brisbane, Australia, Atmos. Environ., 37, 4195-4203.

Morawska, L., Ristovski, Z., Jayaratne, E.R., Keogh, D.U. and Ling, X. (2008) Ambient nano and ultrafine particles from motor vehicle emissions: character- istics, ambient processing and implica- tions on human exposure, Atmos.

Environ., 42,8113-8138.

Morawska, L., He, C., Johnson, G., Guo, H., Uhde, E. and Ayoko, G. (2009) Ultrafine particles in indoor air of a school: possible role of secondary organic aerosols, Environ. Sci. Technol., 43, 9103-9109.

Morawska, L., Afshari, A., Bae, G.N., Buonanno, G., Chao, C.Y.H., Hanninen, O., Hofmann, W., Isaxon, C., Jayaratne, E.R., Pasanen, P., Salthammer, T., Waring, M. and Wierzbicka, A. (2013) Indoor aerosols: from personal exposure to risk assessment, Indoor Air, 23, 462-487.

Mullen, N.A., Bhangar, S., Hering, S.V., Kreisberg, N.M. and Nazaroff, W.W. (2011) Ultrafine particle concentrations and exposures in six elementary school classrooms in northern California, Indoor Air, 21, 77-87.

Norback, D., Wieslander, G., Zhang, X. and Zhao, Z. (2011) Respiratory symptoms, perceived air quality and physiological signs in elementary school pupils in rela- tion to displacement and mixing ventila- tion system: an intervention study, Indoor Air, 21, 427-437.

Park, K., Park, J.Y., Kwak, J.-H., Cho, G.N. and Kim, J.-S. (2008) Seasonal and diurnal variations of ultrafine particle concentration in urban Gwangju, Korea: observation of ultrafine particle events, Atmos. Environ., 42, 788-799.

Rumchev, K., Ourangui, R., Bertolatti, D. and Spickett, J. (2007) Indoor air quality in old and new schools, WIT Trans. Bio- med. Health, 11, 25-32.

Schwartz, J. (2004) Air pollution and children ${ }^{0}$ health, Pediatrics, 113, 1037-1043.

Semmler, M., Seitz, J., Erbe, F., Mayer, P., Heyder, J., Oberdorster, G. and Kreyling, W.G. (2004) Long-term clearance kinetics of inhaled ultrafine insoluble iridium par- ticles from the rat lung, including tran- sient translocation into secondary organs, Inhal. Toxicol., 16, 453-459.

Sioutas, C., Delfino, R. and Singh, M. (2005) Exposure assessment for atmospheric ultrafine particles (UFPs) and implica- tions in epidemiologic research, Environ. Health Perspect., 113, 947-955.

Slezakova, K., Castro, D., Begonha, A., Delerue-Matos, C., Alvim-Ferraz, M.C.M., Morais, S. and Pereira, M.C. (2011) Air pollution from traffic emissions in Oporto, Portugal: health and environmental implications, Microchem. J., 99, 51-59. 
Slezakova, K., Pires, J.C.M., Castro, D., Al-vim-Ferraz, M.C.M., Delerue-

Matos, C., Morais, S. and Pereira, M.C. (2013) PAH air pollution at a Portuguese urban area: carcinogenic risks and sources identifica- tion, Environ. Sci. Pollut. Res., 20, 3932- 3945 .

Stanek, L.W., Sacks, J.D., Dutton, S.J. and Dubois, J.J.B. (2011) Attributing health effects to apportioned components and sources of particulate matter: an evaluation of collective results, Atmos. Environ., $45,5655-5663$.

Stone, V., Johnston, H. and Clift, M.J.D. (2007) Air pollution, ultrafine and nanoparticle toxicology: cellular and molecu- lar interactions, IEEE Trans. Nanobioscience, 6, 331-340.

Terzano, C., Di Stefano, F., Conti, V., Graziani, E. and Petroianni, A. (2010) Air pollution ultrafine particles: toxicity beyond the lung, Eur. Rev. Med. Pharmacol. Sci., 14, 809-821.

Unfried, K., Albrecht, C., Klotz, L.O., Von Mikecz, A., Grether-Beck, S. and Schins, R.P.F. (2007) Cellular responses to nanoparticles: target structures and mechanisms, Nanotoxicology, 1, 52-71.

U.S. Environmental Protection Agency (2011) Exposure Factors Handbook 2011 Edition (Final), Washington, DC, U.S. Environmental Protection Agency.

Wallace, L. (2006) Indoor sources of ultrafine and accumulation mode particles: size distributions, size-resolved concen- trations, and source strengths, Aerosol Sci. Technol., 40, 348-360.

Wang, F., Costabileb, F., Li, H., Fang, D. and Alligrini, I. (2010) Measurements of ultrafine particle size distribution near Rome, Atmos. Res., 98, 69-77.
Wang, Y., Hopke, P.K., Chalupa, D.C. and Utell, M.J. (2011) Long-term study of urban ultrafine particles and other pollutants, Atmos. Environ., 45, 7672-7680.

Weichenthal, S., Dufresne, A., Infante-Rivard, C. and Joseph, L. (2008) Characterizing and predicting ultrafine particle counts in Canadian classrooms during the winter months: model development and evaluation, Environ. Res., 106, 349360.

World Health Organization (2006) Air Quality Guidelines Global Update 2005: Particulate Matter, Ozone, Nitrogen Dioxide, and Sulfur Dioxide, Copenhagen, Denmark, World Health Organization Regional Office for Europe.

Zhang, Q. and Zhu, Y. (2012) Characterizing ultrafine particles and other air pollutants at five schools in South Texas, Indoor Air, $22,33-42$. 